\title{
Hemodialysis Access: The Fistula
}

\author{
Mary Hammes \\ University of Chicago \\ United States
}

\section{Introduction}

The primary aim of this chapter is to understand the importance of placement and maintenance of arteriovenous fistula (AVF) in the patients with advanced renal failure prior to the need for dialysis. Vascular access complications contribute significantly to the morbidity and mortality associated with end-stage renal disease patients on hemodialysis. The major concern this publication will address is that with the recommendation for an increased number of AV fistulas, we are faced with the fact that many fistulas fail, with limited data to understand complications of AVF specifically stenosis and thrombosis. Attempts to understand underlying mechanisms of stenosis and thrombosis will aide in access design, treatment options, and hence improve morbidity and mortality.

The care and outcome of the patient with end-stage renal failure (ESRD) on chronic hemodialysis is dependent on their access. Although a variety of techniques have been developed for providing hemodialysis access, there have been no major advances in the past three decades. This contributes to the fact that hemodialysis access dysfunction is one of the most important causes of morbidity and mortality in the hemodialysis population. In addition, the expense of providing ESRD care in the US is a significant portion of the Medicare budget, totaling $\$ 23.9$ billion in 2007 , of which a significant portion is spent on placement and maintenance of vascular access (USRDS, 2009).

The fistula provides the best outcome and can be placed with the least expense and complication rate when compared to a catheter or graft. Therefore, regional and network indicators promote the placement of AVF. Several recent initiatives have focused on vascular access and ways to improve outcomes. The National Foundation for KidneyDialysis Outcomes Quality Initiative (K-DQOL), End Stage Renal Disease Clinical Performance Measures (CPM) and Fistula First Initiative (FFI) have provided guidelines that mandate fistula access in patients on hemodialysis (Vasquez, 2009). FFI, developed to promote fistula placement, had an initial goal of $40 \%$ of prevalent patients with fistula access. This goal was achieved in 2005, with a goal of $66 \%$ set for 2009. Nationwide, however, there are only $54.4 \%$ of prevalent hemodialysis patients with fistula access as of November, 2009, with the number of fistula access placements falling for the first time in 2007 (USRDS, 2009).

New insights into the care and maintenance of fistula access will help to ensure duration of long term access patency. With national initiatives to place more fistulas, the number of fistulas has and will continue to increase. There are gaps in knowledge as to surveillance, maturation, cannulation techniques and mechanism and treatment of stenosis and thrombosis. The following chapter on fistula access for hemodialysis will help to fill these voids. 


\section{Types of vascular access}

Permanent vascular access in the patient with ESRD on hemodialysis is provided through a central venous catheter (CVC), arteriovenous graft (AVG), or AVF. The central venous access is provided by a cuffed catheter placed subcutaneously in the internal jugular vein. The most frequent complications of CVC with significant clinical consequences include infection and thrombosis; therefore this access is not a recommended option for permanent vascular access. An AVG is placed if the venous or arterial supply is inadequate. It is created by insertion of a synthetic conduit usually polytetrafluororthylene between an artery and vein. AV grafts have a high rate of thrombosis and infection with an average survival of only 2-3 years ( KDQOL, 2006). An AV fistula is created by a surgical anastomosis between and artery and vein. When a fistula is created the vein and artery may be in their normal positions, or the distal end of the vein is moved to a position that is better located for cannulation (vein transposition). A translocation is done when the entire vein is moved from one anatomic location to another requiring an arterial and venous anastomosis.

The fistula with the best outcome is the lower arm radiocephalic (RCF); however this access often fails to mature in the elderly patient with underlying vascular disease, particularly in diabetics (Miller,1999; Rodriquez, 2000). The second recommended fistula is the upper arm brachiocephalic fistula (BCF). This type of fistula is being placed with increased frequency because of the high failure rate of RCF. The third recommended fistula is the brachiobasilic fistula $(\mathrm{BBF})$, which usually involves a two step surgical procedure and may be difficult to cannulate given the medial location of the basilic vein.

\subsection{Radial-cephalic fistula}

The RCF was the first fistula designed in 1966 by Brescia (Brescia, 1966). The RCF is created by an anastomosis between a radial artery and a cephalic vein usually with a transverse

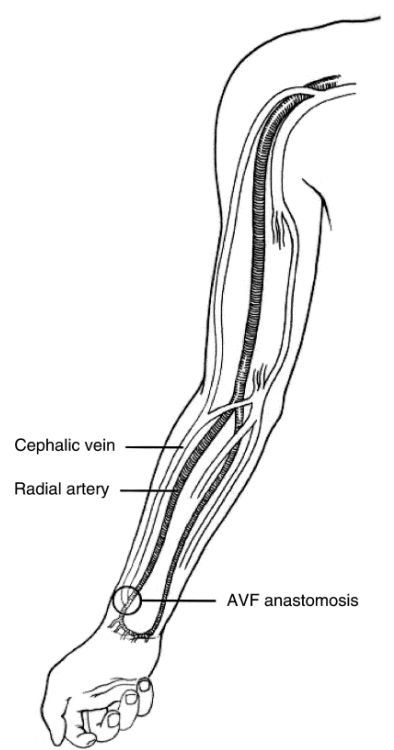

Fig. 1. Radial-cephalic fistula. Figure reprinted by permission from Macmillan Publishers Ltd: Kidney International, 62, 2002 
incision at the wrist (Fig 1). This access is easy to place and once mature and used for dialysis has a low complication rate. The classic Cimino fistula is constructed with a side-to side anastomosis but this design may lead to venous hypertension. Therefore an end-to-side anastomosis is commonly used. The most frequent clinical problem is that this access has a higher primary failure rate when compared to BCF or BBF (Miller, 1999). However, if a RCF matures, the 5 to 10 year cumulative patency rate is 53 and 45 percent respectively (Bonalumi, 1982, Rodriguez, 2000). Placement of a lower arm fistula is desirable as it preserves the upper arm for future use.

\subsection{Brachial-cephalic fistula}

The BCF is a suitable second choice for access (Reubens, 1993). The cephalic vein in the upper arm is larger with increased flow as compared to the lower arm. The anastomosis for a BCF is usually in the antecubital fossa between the brachial artery and cephalic vein (Fig 2). The location of the BCF enables ease of cannulation with the benefit of a large surface area. The major complication with a BCF is the steal syndrome (see complications) as compared to RCF or BBF. In a retrospective review of 2,422 patients with vascular access, the $\mathrm{BBF}$ had a superior patency rate in diabetic pateints when compared to diabetic pateints who had a RCF (Papanikolaou, 2009). The authors even went so far as to argue that the BCF may be the best access option for the older diabetic patient on hemodialysis.

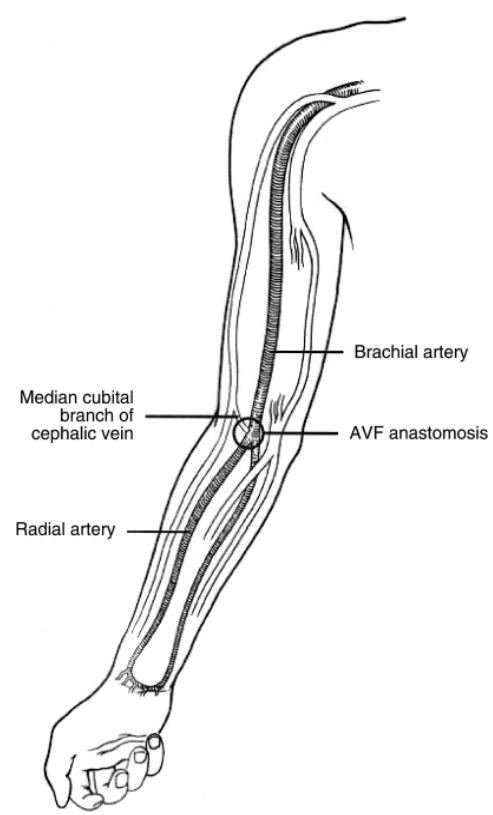

Fig. 2. Brachial-cephalic fistula. Figure reprinted by permission from Macmillan Publishers Ltd: Kidney International, 62, 2002

\subsection{Brachial-basilic fistula}

The BBF is the third choice for fistula placement (Dagher, 1976). Because the basilic vein is less accessible to venipuncture it tends to be better preserved and less involved with 
traumatic post-phlebitic changes when compared to the cephalic vein. When the BBF is placed more surgical skill is required with an initial anastomosis deep between the brachial artery and basilic vein (Fig 3). The BBF is left to mature for two months and then a second surgical procedure is preformed to "lift" the vein to allow ease of cannulation. The anatomic location of this fistula is often located in a position which is difficult to cannulate. Overall, the failure rate of the BBF is worse than BCF or RCF (Taghizadeh, 2003).

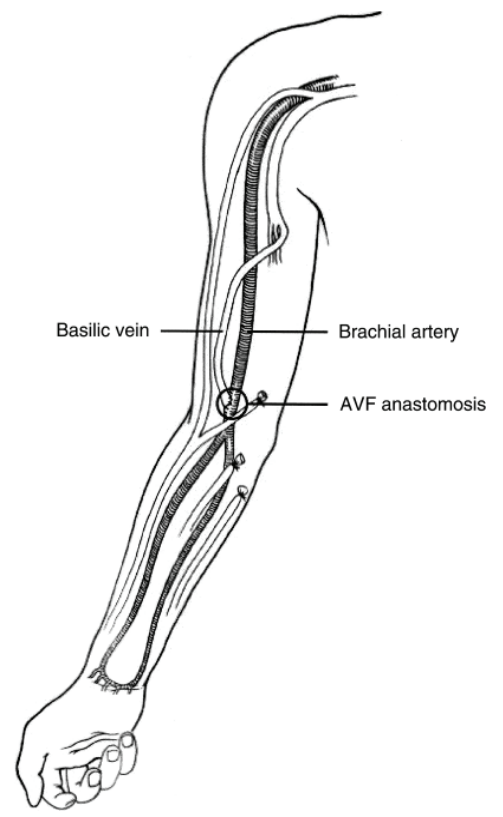

Fig. 3. Brachial-basilic fistula. Figure reprinted by permission from Macmillan Publishers Ltd: Kidney International, 62, 2002

\section{Complications of fistula access}

Even though complications of fistula access are far less than a graft or a catheter, they do occur and need to be addressed. Complications occur in approximately one-third of fistulas and include: aneurysms, infection, stenosis, thrombosis, steal syndrome and heart failure. These complications have historically been classified as early and late failure. The etiology of both early and late are somewhat similar because if the cause is not diagnosed early on it may progress and lead to late access failure. Fistula failure may also be classified as primary defined as a fistula which fails prior to cannulation or secondary defined as failure after a radiologic intervention such as angioplasty or stent or surgical revision.

\subsection{Early failure/complications}

Early failure of an AVF is defined as a fistula which never matures or is unable to be used by three months of time. It is well known from several studies that there is a significant primary failure rate for all AV fistulas that are placed (Schild,2004; Biuckians,2008; Dember 2008). Causes of early fistula failure are due to inflow problems from inadequate arterial supply, anastamotic stenosis which may result from trauma during creation, or outflow 
problems of the venous segment. Outflow problems may occur because of underlying fibrosis of the vein. Other factors which contribute to the primary failure of fistulas include demographic factors such as age, obesity, non-white ethic group, female sex, history of diabetes or peripheral vascular disease (Lok, 2006; Huijbregts, 2008) The size of the underlying vein may also influence the ability of a fistula to mature. A cephalic vein diameter of less than $2.0 \mathrm{~mm}$ on ultrasound in the forearm and less venous distensibility increases the risk of primary failure (Silva, 1998).

A cause of poor maturation is the development of collateral circulation. Often times a fistula is placed and when developing, collateral vessels may form which decrease the amount of flow through the designated vein to be used for cannulation. The physical exam may often help diagnosis this problem as you may palpate extra accessory vessels with an apparent augmentation in the vein when it is occluded. Small assessory vessels less than one-forth the diameter of the main AVF are likely to be insignificant. If a fistula is not maturing by 6 weeks, many algorithms suggest a vengram by 6 weeks. If collateral vessels are identified they may be coiled by interventional radiology techniques or ligated by surgical techniques (Rodriguez, 2000).

Prevention of early fistula thrombosis with pharmacologic intervention has been the subject of several recent trials, which have shown only minimal effect. The Dialysis Outcomes -Practice Patterns Study (DOPPS) noted a lower risk of failure of established fistulas in patients who used aspirin consistently over a year (Hassegawa, 2008). The Dialysis Access Consortium Fistula Trial (DAC) was a multi-center trial which compared the effects of the anti-platlet agent Clopidrogrel with placebo on early fistula failure. The proposed sample size was 1284, but the study was terminated after enrollment of 877 patients as interim data analysis showed that Clopridrogel reduced the risk of fistula thrombosis by $37 \%$ (Dember, 2008). In the DAC study $61 \%$ of newly created fistulas failed. These findings and others have shown a primary failure rate of 31-61\% (Schild,2004; Biuckians,2008; December 2008). This suggests that failure of the fistula to mature is the main obstacle to successful fistula use.

\subsection{Late failure/complications}

Late failure of the fistula is defined as occurring greater than three months after creation and is often due to outflow stenosis. Venous stenosis occurs less frequently in AVF when compared to AVG, but nonetheless it is a common cause of AVF failure. Venous stenosis is usually detected clinically by symptoms of swelling of the extremity, prolonged bleeding post dialysis, difficulty cannulation or poor clearance. When these symptoms develop, the patient may be sent for an ultrasound for diagnosis or more commonly an interventional venogram. The venogram is desirable as a patient may have the venogram/angioplasty as a treatment option during the same procedure.

The most common anatomic location for an outflow stenosis in a RCF is $3 \mathrm{~cm}$ from the arteriovenous anastomaosis (Rajan, 2004). Outflow stenosis in RCF may be treated successfully by angioplasty with favorable primary and secondary patency rates (Rajan, 2004). Inflow lesions from inadequate arterial flow are often detected by a negative arterial pressure during hemodialysis and by physical examination using pulse augmentation. An arterial lesion may be present in $15-30 \%$ of fistulas (Leon, 2008). This type of lesion also is successfully treated by angioplasty or surgical revision (Turmel-Rodrigues, 2000).

One of the leading causes of failure of BCF is due to stenosis in the cephalic arch, which is the final bend in the cephalic vein prior to entry into the axillary vein (Fig 4). Cephalic arch stenosis (CAS) is found to occur in up to $77 \%$ of patients with BCF compared to $30 \%$ of 
patients with RCF with an average clinical significance at 2 years necessitating a venogram with intervention. The risk of development of CAS is less in diabetics for unclear reasons (Hammes, 2008). The BCF has been shown to be a superior access in older diabetic patients (Papanikolaou, 2009). Once CAS occurs it leads to head and neck swelling, high venous pressures and resultant thrombosis with complex treatment options. The arch is elastic, resistant to repeated angioplasty and often requires stent placement resulting in further stenosis (Hammes, 2008).

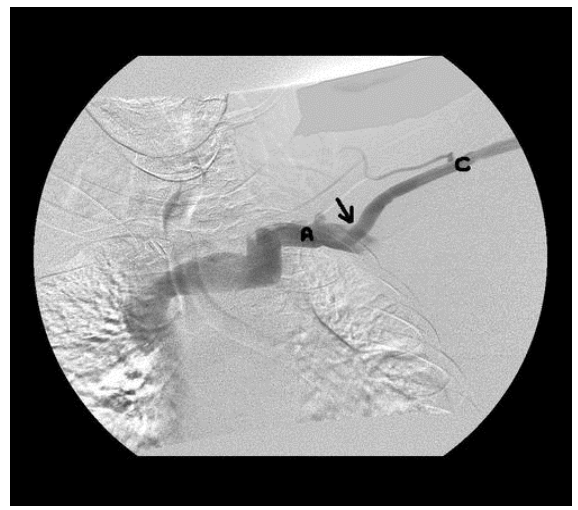

Fig. 4. Radiograph of Cephalic arch represented by arrow; $\mathrm{C}$ is the cephalic vein; $\mathrm{A}$ is the axillary vein

\subsubsection{Aneurysms}

The incidence of aneurysm formation in fistulas varies in studies from 5-7\% (Lo, 2007). A traditional definition of an aneurysm is that it is considered true if it involves all layers of a venous wall or false if the wall is lined by thrombus or fibrous tissue. Aneurisms form for many reasons which include repeated cannulation at repetitive sites or altered turbulent blood flow from stenosis. As aneurysms are both a physiologic and cosmetic complication that may lead to the need for surgical revision and subsequent failure an approach to address aneurysms should be developed. Moreover, if a thrombosis occurs and significant aneurysm is present, the clot burden may be large and the thrombectomy procedure may be difficult. Aneurysms may also lead to an increased infection risk and prolonged bleeding post dialysis.

The treatment of aneurysms is prevention and if they form surgical correction. Preventative measures start with careful cannulation techniques (see cannulation techniques). Surgical options for correction include longitudinal stapling to reduce the lumen, open placation, excision with primary anastomosis, excision with interposition of prosthetic graft, and ligation (Pierce, 2007; Lo, 2007; Georgiadis, 2008). All of these techniques have been used with success and a decision for surgical treatment should be made on a case-by-case basis.

\subsubsection{Steal syndrome}

Steal syndrome is defined as distal hypoperfusion of the extremity in patients with severe peripheral vascular disease due to shunting of arterial blood flow into the fistula (Leon 2007). Reverse flow occurs if the diameter of the fistula opening is greater than the diameter 
of the feeding artery. Symptomatic steal occurs when there is a failure of adequate collateral flow and/or excessive blood flow. This problem complicates approximately 3-5\% of fistulas and grafts. It is likely to occur more frequently with BCF $(6 \%)$ verses RCF. Hand ischemia from steal syndrome may require distal revascularization with interval ligation (DRIL) procedure or complete ligation in severe cases. The DRIL procedure was first proposed by Harry Schanzer in 1988 (Schanzer, 1988). A short distal bypass is created and the artery just distal to the AV anastomosis is ligated. The DRIL procedure has been used successfully to relieve the ischemic symptoms in a significant number of patients with steal syndrome (Waltz, 2007).

\subsubsection{Infection}

The incidence of infection of an AVF is relatively low given that the native vein is used as a conduit. Predisposing factors to infection include: inadequate skin disinfection prior to cannulation, pseudo aneurisms, perifistular hematomas (often due to inappropriate cannulation), puritis with skin excoriation over needle sites, or the use of the fistula for IV drug use. Infection occurring in native fistulas can usually be treated with intravenous antibiotics and, if necessary surgical drainage.

\subsubsection{Cardiac failure}

AVF creation causes an increased blood flow and resultant cardiac output, Creation of a fistula is associated with a $15 \%$ increase in cardiac output and $4 \%$ increase in left ventricular end-diastolic diameter There is also an observed increase in ANP and BNP (Iwashima, 2002). These changes often go unnoticed, however high output failure from fistula access occurs in less than $1 \%$ of cases. The decision for permanent access placement in patients with category III or IV heart failure is challenging. Patients with ESRD in this subset should be considered for peritoneal dialysis. If this is not possible a lower arm fistula could be considered (decreased blood flow when compared to an upper arm fistula) with close monitor for worsened heart failure.

\subsubsection{Venous hypertension}

Venous hypertension in an extremity occurs because of incompetent venous valves or central venous stenosis. This problem may cause severe swelling in an extremity with associated complications of skin discoloration and thickening predisposing to infection. Doppler exam is used for diagnosis to demonstrate reversal of blood flow. Diagnosis and treatment with a venogram by an interventional radiologist may also be preformed. Treatment is aimed at correcting the underlying problem if present. Careful clinical practice includes obtaining a central venograms prior to fistula placement if there are clinical clues of venous hypertension such as, a history of ipsilateral catheter placement or dialated chest wall veins.

\subsubsection{Median nerve injury}

A very difficult problem with AVF access is median nerve injury. It may occur from ischemic injury from steal, compression of the nerve if there is extravasation of blood or local amyloid deposition in long term dialysis patients. The treatment is first to rule out vascular compromise and confirm diagnosis with an EMG. If traditional therapy to treat neuropathy does not resolve the pain, the fistula may need to be ligated. 


\section{Physiology of a fistula access}

The creation of a fistula results in blood flow from an artery to a vein that is inherently nonphysiologic in many ways. The initial flow rate in the radial artery of $20-30 \mathrm{~mL} / \mathrm{min}$ increases to $200-300 \mathrm{~mL} / \mathrm{min}$ immediately after creation of an AV fistula, reaching flow rates of $600-1200 \mathrm{~mL} / \mathrm{min}$ after maturation (Wedgewood, 1984). In addition, the blood flow in the vein is not pulsatile prior to fistula insertion, whereas it is after the fistula is created. High fistula blood flow, a prerequisite for venous dilation and a requirement for easy cannulation and adequate dialysis, is accompanied by high arterial pressure being transmitted to the vein. This intense increase in flow rate and pressure has a profound effect on the hemodynamics in the downstream vein (Albayrak, 2006). The dramatically increased arterial blood flow at the time of fistula creation ultimately leads to an overall increase in shear stress, early on an observed low shear stress is evident which is thought to contribute to intimal hyperplasia and resultant venous stenosis and ultimate thrombosis.

\section{Mechanism of stenosis and thrombosis}

The mechanism responsible for the development of intimal hyperplasia and resultant venous stenosis is poorly understood. Stenosis, leading to thrombosis may require repeated procedures to maintain access patency and is the number one contributor to access failure. Several factors contributing to the development of intimal hyperplasia include: endothelial cell (EC) dysfunction from high blood flow and resultant shear stress; underlying histology of the vein; geometry of the anastomosis and angles of bends in vein; vascular remodeling; oxidative stress and inflammatory mediators that result from the hemodialysis procedure itself, and rheological factors such as viscosity (Table 1). Future studies that look at these factors will guide treatment trials to improve outcomes.

\begin{tabular}{|c|}
\hline Shear Stress \\
\hline Histology \\
\hline Geometry \\
\hline Vascular Remodeling \\
\hline Oxidative Stress \\
\hline Rheology \\
\hline
\end{tabular}

Table 1. Factors influencing Intimal Hyperplasia

\subsection{Shear stress}

When a fistula is created a vein is subjected to intense arterial pressure and flow. A vein is asked to behave as an artery perhaps without the anatomic make-up to undergo remodeling. The anatomy and physiology in a native artery is a constructive model to understand the mechanism of stenosis as it applies to venous stenosis in an AVF. A blood vessel is made of endothelial cells (EC) which form the lining of the vessel. These cells are normally aligned longitudinally. Vascular smooth muscle (VSM) cells align around the EC circumferentially. An arteriole has a thicken VSM layer when compared to a vein. Blood flow exerts pressure on the EC in a perpendicular direction. Shear stress is the frictional force per unit area from flowing blood which acts parallel to the EC that line the vessel. In 
straight regions of vessels, blood flow is in the same direction (laminar) and EC are quiescent with high laminar shear stress and resultant low oxidative stress, cell turnover and permeability. When a fistula is created blood vessels divide or curve and complex flow patterns may develop. When this happens EC are subjected to disturbed shear stress with higher levels of oxidative stress and inflammation which may result in vascular remodeling (Hahn, 2009).

The anastomosis of the fistula is also important to the development of intimal hyperplasia. The primary mode of failure of a fistula access relates to outflow stenosis caused by anastomotic intimal hyperplasia. When an anastomosis is created, the trauma causes activation of chemotactic factors which result in smooth muscle migration from the media to the intima. The resultant EC dysfunction with abnormal NO production may cause dysregulation of vascular tone. Smooth muscle cells continue to migrate and proliferate with resultant intimal hyperplasia. The end result may be decreased anastomotic compliance (Lin 2005).

This schematic of this process eventually leading to fistula failure is depicted in Figure 5. When a fistula is placed there is a bend or curve created at the anastomosis. This causes a turbulent blood flow, injury to EC, decreased WSS and resultant intimal hyperplasia. There is flow restriction that results and eventual worsened intimal hyperplasia that leads to further flow restriction with the end result of stenosis. The stenotic surface leads to heamostasis and further thrombus formation. Ultimately the fistula fails as a consequence of the stenosis.

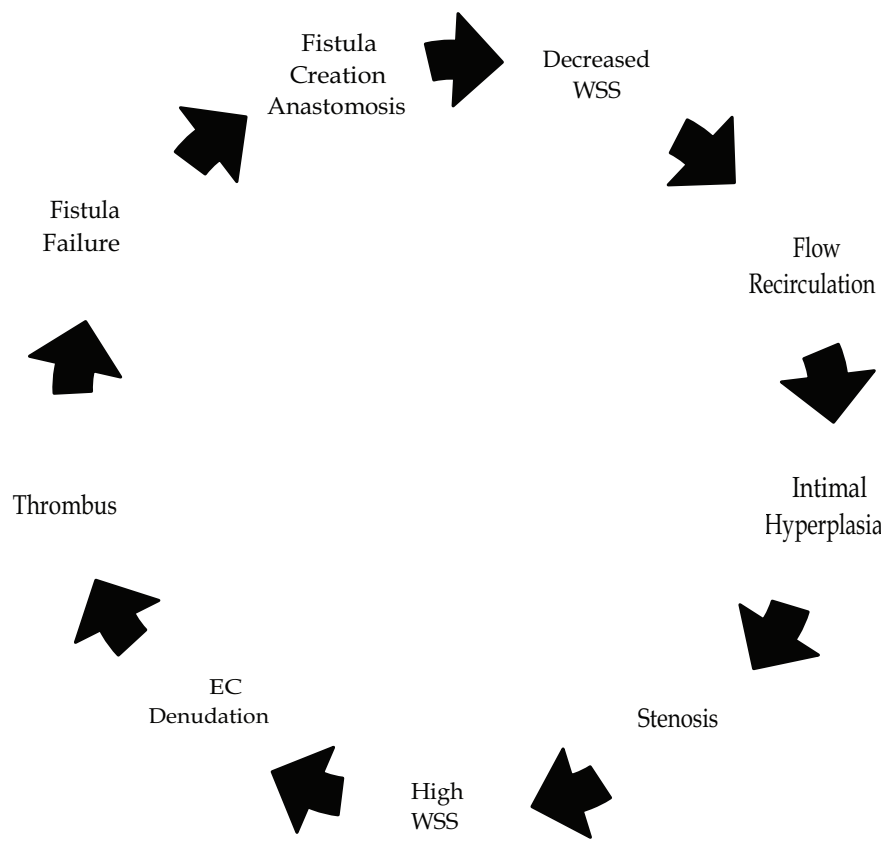

Fig. 5. Proposed cycle of fistula creation which eventually leads to intimal hyperplasia and fistula failure 


\subsection{Histology of the vein}

Arterial and venous dialation is critical for fistula maturation. There is no exact definition of fistula maturation, but it is considered mature when it can routinely be cannulated with 2 needles and deliver a minimum blood flow (typically 350 to $450 \mathrm{~mL} / \mathrm{min}$ ) for a total duration of dialysis ( usually 3-5 hours). Impaired dialation may be due to both structural and or functional factors. Pathologic analysis of the muscular artery and cephalic vein from patients with ESRD have demonstrated neo-intimal thickening (Wall, 2006). Other findings include increase radial artery intimal-media thickness which is correlated with decreased fistula maturation (Dixon, 2009). Many of these pathologic findings are present in the vein at the time of fistula placement and influence the outcome of the fistula.

\subsection{Geometry}

A fistula is created by an anastomosis creating a curve or bend to the vessel. The anastomosis is usually by and end-to-side design but occasionally by a side-to-side design. This creates a change from laminar flow to turbulent flow and as described above, the result is increased shear stress on EC with resultant intimal hyperplasia. This process may also be occurring in native conditions such as occurs in the cephalic arch. Hammes reviewed 45 venograms from BCF access and made measurements of the cephalic arch angle (global) and minimum radius of curvature and cephalic vein diameter (local measurements). Both global and local measurements showed evidence of having two distinct arch angles. Diabetics more commonly had a wider angle and less evidence of cephalic arch stenosis whereas non-diabetics had a wider angle and increased incidence of stenosis. (Hammes, 2009). These findings suggest that geometry influences hemodynamics and resultant stenosis.

\subsection{Vascular remodeling}

Vascular remodeling, first described by Glagov in 1987, refers to the ability of a vessel to change dimensions by vasoconstriction or vasodilatation, adjusting to flow changes to prevent stenosis. He reported that atherosclerotic arterial lumen narrowing was not simply the result of enlargement of the plaque lesion, but rather the vascular failure of the vessel to remodel to maintain a diameter so as not to inhibit blood flow (Korshunov, 2007). In a fistula, the vein and artery must remodel to a certain degree so as not to develop intimal hyperplasia or fibrosis.

In experimental models, when a fistula is first created, the cross-sectional area of the arterial wall increases with increased elastin, collagen and possibly smooth muscle cells( Driss, 1997). In human studies, this does not occur, but after a year, the artery appears to thicken circumferentially which may lead to defective remodeling (Dammers, 2005). Venous dialation occurs rapidly after the anastomosis due to increased areterial pressure and continues to dilate over several weeks attaining blood flow by 4-6 weeks (Dixon, 2006). Over time, venous thickening occurs and is characterized by intimal hyperplasia, smooth muscle cell proliferation and increased extracellular matrix production (Nath, 2003). If intimal hyperplasia develops and leads to clinically significant stenosis a venogram with angioplasty is usually preformed to dialate the venous stenosis. Early on the lesion may be responsive to angioplasty. At this point, there is no doubt remodeling taking place that is maintaining the diameter of the lumen. Over time with repeated use of the fistula, trauma 
and resultant inflammation may develop with repeated interventional angiography ultimately leading to fibrosis of the vein and eventual access failure.

\subsection{Oxidative stress and inflammation}

When a fistula is placed, matures and is cannulated for hemodialysis an inflammatory environment is created which leads to changes in vascular biology that may contribute to the development of intimal hyperplasia. EC dysfunction from altered shear stress as described above leads to release of nitric oxide and arterial dialation in response to increase flow rates (Dixon, 2009). It has been observed that when arterial dialation occurs, there is continued increase in shear stress that does not always normalize, suggesting that arterial adaptation to fistula creation may be incomplete. (Damers, 2005)

With evidence of histologic inflammation, there is upregulation of numerous cytokine and genes the cause smooth muscle proliferation and collagen deposition. Histologic injury to the vein is mediated by easly upregulation of mRNA for MCP-1, PAI-1, and endothelin -1 and later upregulation of mRNA for fibrogenic cytokine, transforming growth factor-B. (Dixon 2009). These studies demonstrate that the vein responds to pressure and shear stress by upregulating genes that lead to NIH. Future attempts to decrease these inflammatory mediators with pharmacologic therapy may prove effective to avert the inevitable intimal hyperplasia and fibrosis that may develop.

\subsection{Rheology}

Another significant factor which affects blood flow through a fistula is rheology, the characteristics of blood cells. The size, shape, deformeability, aggregation and whole blood viscosity (WBV) of blood have been shown to affect circulatory hemodynamics (Cho, 2008). Increased WBV may be detrimental causing increased peripheral resistance and sludging in post capillary venules (Pop, 2002). Patients with a history of peripheral vascular disease and diabetes, which are common in patients with ESRD, are associated with increased WBV. Over half of patients with ESRD have underlying diabetes and hypertension and it is predicted that these patients have elevated WBV.

Given that elevated WBV causes impaired circulation, it is likely that rheology, specifically WBV, contributes to the development of fistula stenosis and thrombosis. This area is the subject of future investigation.

\section{Cannulation techniques for AVF}

When a patient begins hemodialysis the start of hemodialysis is accompanied with anxiety regarding the surgical placement of the access along with needle cannulation. Excessive dilation of the fistula may be of major concern for patients. These issues should be addressed through education and not prevent patients from receiving the benefits of a well functioning access. The education and timing of the access placement to coincide with the initiation of hemodialysis is of paramount importance. It is imperative that attention to the placement of dialysis access is discussed when it is determined that a patient will need chronic hemodialysis.

Once an AVF is surgically placed, it usually takes two months for the vein to mature to allow for cannulation. Although some fistulas mature within weeks, others may require up 
to 6 months before they provide reliable hemodialysis access so catheters may be removed. The timing of when to cannulate is determined by clinical examination. The vein should be palpable, visualized and long enough to accommodate two needles. The fistula should be within $1 \mathrm{~cm}$ of the skin surface in order for reliable cannulation. If the venous segment is too deep, a transposition may be preformed. There is consensus that fistulas should be 1 eft to mature for at least 30 days. In general cannulation before 2 weeks should be avoided.

Accurate cannulation of the fistula by experienced personal is mandatory for successful outcomes. Trauma including laceration and infiltration of the vein may cause local damage making future cannulation difficult. It has been estimated that one infiltration may delay catheter removal by 3 months. Techniques for cannulation include rotation of sites or the buttonhole technique. The buttonhole cannulation method is gaining increased acceptance among patients as there is less pain with the needle stick and decreased long term risk of aneurism formation.

\subsection{Rope-ladder technique}

The rope and ladder technique is the traditional method for access cannulation. This was developed so as not to weaken the integrity of the vein with repeated cannulation. The fistula is thought of as a rope or ladder and the needles are placed one to two inches apart, similar to rungs on a ladder or knots in a rope. The site is left to heal prior to the subsequent cannulation. This technique is useful to prevent aneurysms and prolong the life of the fistula. Complications may arise if the same site is cannulated which may be the case if sites are limited and one site becomes easier to cannulate.

\subsection{Buttonhole technique}

The buttonhole technique was introduced in Poland over 25 years ago when dialysis supplies including AVF needles were limited (Twardowski, 1979). AVF needles were reused for multiple cannulations and become dull with repeated use. The "dull" needle would enter smoothly if the exact same cannulation site and angle was used. The buttonhole technique was used to successfully solve the dull needle problem, with this method, the needles are inserted at exactly the same spot at consecutive dialysis sessions, establishing a channel in the AVF. The procedure of the buttonhole cannulation involves: identifying an optimal site such as a long venous segment without previous trauma, removal of the scab from previous puncture site using an aseptic technique and cannulation of the fistula at exactly same angle (approximately $25^{\circ}$ ). Initially sharp needles are used but once the track is developed which usually takes 2 weeks a blunt needle is used. This method has gained wide acceptance among patients as there is less pain associated with the cannulation and a decreased incidence of aneurysms. The buttonhole technique is gaining widespread acceptance in patients who practice self-cannulation (Verhallen, 2007). It is a technique that promotes independent self-care.

The main risk associated with buttonhole cannulation is infection. There may also be problems with "one-site-itis" which occurs if the same site is stuck technique include those with heavily scarred fibrous or a large amount of subcutaneous tissue in the upper arm. multiple times, the skin can become heavily scarred. Both infection or development of a fibrous track require placement of a new buttonhole. 


\subsection{Self cannulation}

Patients who are able to use self cannulation have excellent outcomes, establishing independence, confidence and less pain. The technique of self cannulation allows the patient to feel where to place the needles and with experience there is a lower risk of infiltrations. This is an excellent cannulation option for home hemodialysis.

\section{Routine surveillance}

While fistula access is recommended for all patients with ESRD on hemodialysis, complications such as stenosis and resultant thrombosis lead to access failure. Therefore, surveillance of hemodialysis access is mandated by regulatory agencies (NKF: K/DOQI, 2006). Prior research attempts to substantiate a surveillance protocol for AV grafts have failed, showing no improvement in the outcome of thrombosis. There is a paucity of data on the benefit of surveillance for fistulas (Allon 2009). Once the factors that cause venous stenosis in fistulas are known, early detection provides the necessary framework to develop protocols to mitigate the onset of intimal hyperplasia. Treatment trials in future studies could then be initiated to change factors that contribute to venous stenosis.

Although there is a lack of adequate surveillance methods to detect fistula stenosis prior to thrombosis, there are some clues in the physical exam that may prove helpful in clinical practice. The physical examination may be the best test as to fistula adequacy for dialysis. Pre-procedure physical examination has been shown to accurately detect significant venous stenosis. The pre-dialysis physical exam of the fistula to detect significant stenosis may include: inspection, palpation from the anastomosis all the way to the chest wall, and auscultation. The characteristics of the pulse such as pulsatile, normal or weak, and if the thrill or bruit is continuous or discontinuous should be noted. Pulse augmentation and arm elevation tests may also be preformed to detect inflow or outflow stenosis. These elements of the physical exam have been reproduced and substantiated to correlate with venous stenosis (Asif, 2007).

\section{Conclusions}

This chapter has reviewed important aspects of AVF access for patient with ESRD on hemodialysis. The current enigma is that with increased need for placement the failure rate is high. Multiple factors cause fistula failure including: underlying demographic variables, stress of the dialysis treatment itself, along with flow changes and characteristics as illustrated in Fig. 6. Careful research to identify a comprehensive understanding of these factors will enhance fistula maturation thereby improving the outcomes for patients with ESRD on hemodialysis.

The AVF is by far the best access with the least risk of complications for patients with ESRD. If a patient starts hemodialysis with a mature fistula, their transition to renal replacement therapy occurs with less risk of morbidity and mortality. As more fistulas are being placed, there is an increased awareness of complications including venous stenosis. We need to review and improve the surgical techniques of fistula placement and maintenance while optimizing novel therapies that promote fistula maturation. The etiology of venous stenosis in an AVF is the subject of future investigation with treatment trials to follow. 


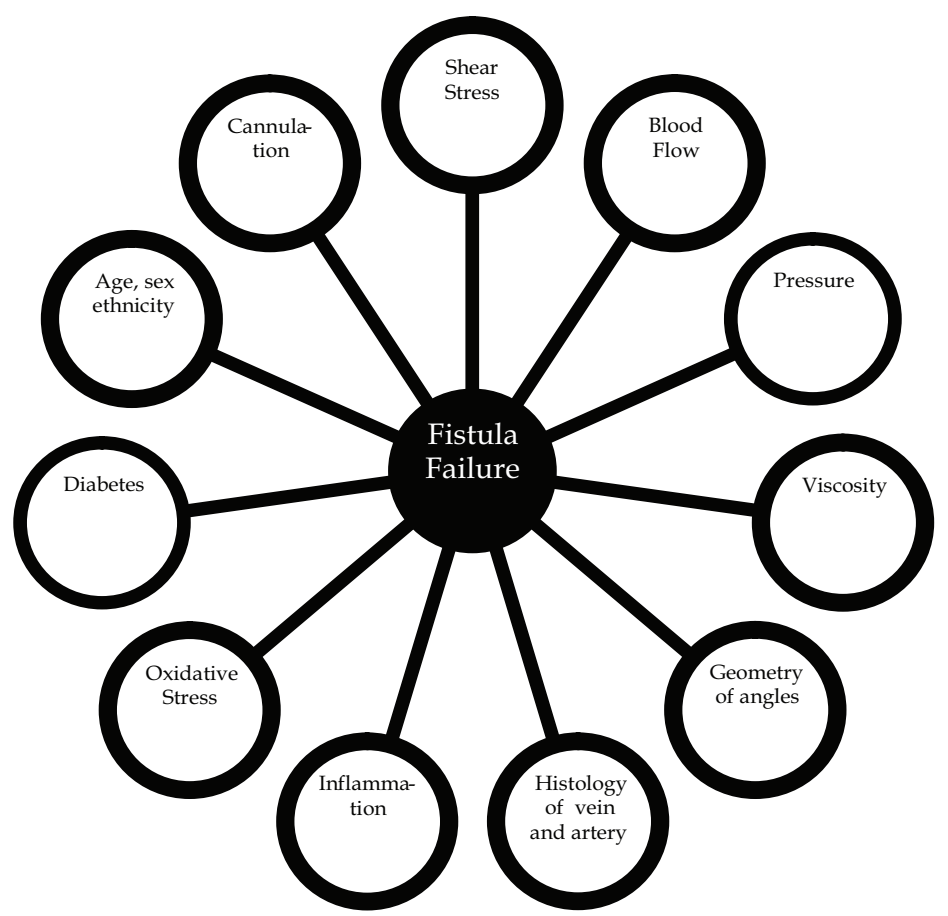

Fig. 6. Factors contributing to fistula failure

\section{References}

Albayrak R, Yuksel S, Colbay M, s B, Acarturk G, Haktanir A \& Karaman O. (2006). Hemodynamic changes in the cephalic vein of patients with hemodialysis arteriovenous fistula. J Clinical Ultrasound, Vol.35, No.3, pp.133-137, (April, 2006), PMID 17274035

Allon M. (2007). Current management of vascular access. Clin J Am Soc Nephrol Vol.2 , No.4, (July, 2007), pp. 786-800, PMID 17699495, ISSN 1555-9041/204-0786

Asf A, Leon C, Oroco-Vargas CO, Krishnamurthy G, Choi KL, Mercado C, Merrill D, Thomas I, Salmon L, Artikov S \& Bourgoignie JJ. (2007). Accuracy of physical examination in the detection of arteriovenous fistula stenosis. Clin J Am Soc Nephrol, Vol.2, No.6, (November, 2007), pp. 1191-1194, PMID 17928468, ISSN 1555-9041/2061191

Bonalumi U, Civalleri D, Rovida S, Adami GF, Gianetta E, \& Griffanti-Bartoli F. (1982). Nine years experience with end-to-end arteriovenous fistula at the "anatomical snuffbox" for maintenance haemodialysis. Br J Surg, Vol.69, No.8, (August 1982), pp. 486-488 PMID 7104641

Biuckians A. Scott EC, Meier GH, Panneton JM, \& Glickman MH. (2008). The natural history of autologous fistulas as first-time dialysis access in the K-DOQI era. J Vasc Surg, Vol.47, No.2, (Feburary, 2008), pp.415-421, PMID 18241764 
Brescia MJ, Cimino JE, Appel K\& Hurwich BJ.(1966). Chronic hemodialysis using venipucture and a surgically creat arteriovenous fistula. $N$ Engl J Med, Vol. 275, No. 20, (November, 1966), pp.1089-1092, PMID 5923023

Cho YI, Mooney MP\& Cho DJ. (2008). Hemorheological Disorders in Diabetes Mellitus. J of Diabetes Sci Technol, Vol.2, No.6, (November, 2008), pp. 1130-1138 PMID 19885302

Dagher F, Gelber R, Ramos E\& Sadler J. (1976) The use of basilic vein and brachial artery as an A-V fistula for long term hemodialysis. J Surg Res, Vol.20, No.4, (April, 1976), pp.373-376, PMID 933493

Damers R,Tordoir JH, Kooman JP, Welton RJ, Hameleers IM, Kitslaar PJ, Hoeks AP (2005). The effect of flow changes on the arterial system proximal to the arteriovenous fistula for hemodialysis. Ultrasound Med Biol, Vol.3, No.10, (October, 2005) pp. 13271333, ISSN 16223635

Dember LM, Beck GJ, Alton M, Delmez JA, Dixon BS, Greenberg A, Himmelfarb J, Vasquez MA, Gassman JJ, Greene T, Radeva MK, Braden GL, Ikizler T, Rocco MV, Davidson IJ, Kaufman JS, Meyers LM, Kusek JW, \& Feldman HI, Dialysis Access Consortium Study Group (2008). Effect of clopidrogigrel on early failure of arteriovenous fistulas for hemodialysis: a randomized controlled trial. JAMA, Vol. 299, No.18, (May, 2008), pp.2164-2171, PMID 18477783

Dixon BS. (2006) Why don't fistulas mature? Kidney Int, Vol.70, No.8, (October, 2006), pp. 1413-1422, PMID 16883317

Driss BA, Benessiano J, Poitevan P, Poitevn P, Levy BI,\& Michel JB (1997), Arterial expansive remodeling induced by high blood flows. Am J Physiol, Vol.272, No.2 Pt 2, (October, 2005) pp.H851-H858, PMID 9124448 Georgiadis GS, Lazzarides MK, Panagoutsos SA, Kantartzi KM, Lambidis CD, Staramos

DN, Vargemezis. (2008) Surgical revision of complicated false and true vascular accessrelated aneurysms. J Vasc Surg, Vol.47, No.6, (June, 2008) pp.1284-91, PMID 18514844

Hahn C, Schwartz MA. (2009) Mechanotransduction in vascular physiology and atherogenosis. Nature Reviews Molecular Cell Biology, 10, (January, 2009) pp.3-62, PMID 1917332

Hammes MS, Boghosian ME, Cassel KW, Funaki B, Coe FL. (2009). Characteristic differences in cephalic arch geometry for diabetic and non-diabetic ESRD patients. Nephrol Dial Transplant, Vol.24, No.7, (July, 2009) pp. 2190-2194, PMID 19244227

Hammes M, Funaki B, Coe FL. (2008). Cephalic arch stenosis in patients with fistula access for hemodialysis: relationship to diabetes and thrombosis. Hemodialysis International, Vol.12, No.1, (January, 2008), pp.85-89, PMID 18271847

Hasegawa T, Elder SJ, Bragg-Gresham JL, Pisom RL, Yamazakis S, Akizawa J, Tadou IM, Port FK, \& Fukuham S (2008). Consistent aspirin use associated with improved arteriovenous fiatula survival among incident hemodialysis patients in the dialysis outcomes and practice patterns study. Clin J Am Soc Nephrol Vol. 3, No.5, (September, 2008) pp.1373-8, PMID 18596119

Huijbrets HJ, Bots ML, Wittens CH, Schrama YC, Moll FL, Blankenstien J, Cimino Study Group (2008). Hemodialysis arteriovenous fistula patency revisited: results of a 
prospective, multicenter initiative. Clin J Am Soc Nephrol, Vol.3, No.3, (May, 2008) pp.714-721, PMID 18256379

Iwashima Y, Horio T, Takami Y, Inenega T, Nishikimi T, Takishitas, Kawano Y, (2002). Effects of the creation of arteriovenous fistula for hemodialysis on cardiac function and natriurectic peptide levels in CRF. Am J Kidney Dis, Vol. 40, No.5, (November, 2002), pp. 974-982, PMID 12407642

K-DOQI. (2006). Clinical practice guidelines for vascular access. Am J Kidney Dis, Vol.48, No. S1, (July, 2006) pp.S176-S247, PMID 16813991

Korshunov VA, Schwartz SM \& Berk BC. (2007). Vascular remodeling: hemodynamic and biochemical mechanisms underlying Glagov's phenomenon. Arterioscler Thromb Vasc Biol, Vol. 27, No.8, (July, 2007) pp.1722-1728, PMID 17541029

Leon C, Asif A. (2007) Arteriovenous access and hand pain: the distal hypoperfusion ischemic syndrome. Clin J Am Soc Nephrol , Vol. 2, No.1, (Januray, 2007) pp.175-183, ISSN 17699402

Lin PH, Bush RL, Nguyen L, Guerrero MA, Chen C \& Lumsden AB. (2005) Anastomotic strategies to improve hemodialysis access patency - a review. Vasc Endovasc Surg, Vol. 39, No.2, (March-April, 2005) pp. 135-142, PMID 15806274

Lo HY, Tan SG. (2007) Ateriovenous fistula aneurysm - plicate, not ligate. Ann Acad Med Singapore, Vol. 36, No.10, (October, 2007), pp.851-853, PMID 17987237

Lok CE, Allon M, Moist L, Oliver MJ, Shah H, \& Zimmerman D. (2006) Risk equation determining unsuccessful cannulation events and failure to maturation in arteriovenous fistulas (REDUCE FTM 1). J Am Soc Nephrol, Vol.17, No.11, (November, 2006), pp.3204-12, PMID 16988062

Miller PE, Tolwani A, Luscy CP, Deierhoi MH, Bailey R, Redden DT \& Allon M (1999) Predictors of adequacy of arteriovenous fistulas in hemodialysis patients. Kidney Inter, Vol.57, No. 1 (July, 1999, pp.347-8 PMID 10411703

Papanikolaou V, Papagiannis A, Vrochides D, Imvrios G, Gakis D, Fouzas I, Antoniadis N, Takoudas D.(2009) The natural history of vascular access for hemodialysis: A single center study of 2,422 patients. Surgery Vol. 145, No.3, (February, 2009), pp.272-9, PMID 19231579

Pasklinsky G, Meisner RJ, Labropoulos N, Leon L, Gasparis AP, Landao D, Tassiopoulos AK \& Pappas PJ. (2011).Management of true aneurysms of hemodialysis access fistulas. J Vasc Surg (January, 2011), doi:10.1016/j.jvs.2010.11.100,PMID 21276676

Pierce GE, Thomas JH, Fenton JR. (2007) Novel repair of venous aneurisms secondary to arteriovenous dialysis fistula, Vasc Endovascular Surg, 41(1), (Feburay-March, 2007), pp. 55-60, PMID 17277244

Pop GAM, Duncker DJ, Gardien P, Vranckx P, Versluis S, Hasan D \& Slager CJ. The clinical significance of whole blood viscosity in (cardio)vascular medicine. Netherlands Heart Journal, Vol. 10, No. 12, (December, 2002), pp. 512-516

Port FK, Pisoni RL, Bommer J, Locatelli F, Jadoul M, Eknoyan G, Kurokawa K, Canaud BJ, Finley M \&Young EW. (2006) Improving outcomes for dialysis patients in the International Dialysis Outcomes and Practice Patterns Study. Clin J Am Soc Nephrol, Vol. 1, No.2, (March, 2006) pp.246-255, PMID 17699213 
Rajan DJ, Bunston S, Misra S, Pinto R \& Lok CE. (2004) Dysfunctional autogenous hemodialysis fistulas: outcomes after angioplasty-are there clinical predictors of patency? Radiology, Vol. 232, No.2, (August, 2004), pp. 508-515, PMID 15286321

Rodriguez JA, Armandans L, Ferrer E, Olmos A, Cordina S, Bartolome J, Borrelas J, Piers L. (2000) The function of permanent access. Nephrol Dial Transplant, Vol.15, No.3, (March, 2000), pp. 402-408, PMID10692528

Roy-Chaudury P, Sukhatme VP, Cheung AK.(2008). Hemodialysisvacular access dysfunction: a cellular and molecular viewpoint. J Am Soc Nephrol, Vol. 17, No.4, (April, 2008). pp. 1112-1127 ISSN 1046-6673/1704-1112 PMID 16565259

Ruebens F, Wellington JL. (1993) Brachiocephalic fistula: a useful alternative for vascular access in chronic hemodialysis. Cardiovasc Surg Vol.1, No.2, (April, 1993), pp. 12830, PMID 8076013

Schanzer H, Schwartz M, Harrington E, Haimov M (1988). "Treatment of ischemia due to "steal" by arteriovenous fistula with distal artery ligation and revascularization.". J Vasc Surg Vol. 7, No.6,(June, 1988), pp. 770-773. PMID 3373618

Schilid AF, Prieto J, Glenn M, Livingstone J, Alfieri K, \& Raines J. (2004). Maturation and fistula rates in a large series of arteriovenous dialysis access fistulas. Vasc Endovasc Surg, Vol. 38, No. 5, (October, 2004),pp. 449-453. PMID 15490043

Silva MB, Hobson RW, Pappas PJ, Jamil Z, Anaki CT, Goldberg MC, Gwertzman G, Padberg FJ (1998), A strategy for increasing use of autogenous hemodialysis access procedures: impact of preoperative noninvasive evaluation. J Vasc Surg, Vol. 27, No.2, (Febuary, 1998), pp.302, PMID 9510284

Taghizadah A, Dasgupta P, Khan MS, Taylor J, Koffman G.(2003) Long-term outcomes of brachiobasilic transposition fistulas for haemodialysis. Eur J Vasc Endovasc Surg, Vol. 26, No.6, (December, 2003), pp. 670-672, PMID 14603429

Tessitore N, Mansueto G, Bedogna V, Lipari G, Poli A, Gammaro L, Baggio E, Morana G, Loschiavo C, Laudon A, Oldrizzi L, Maschio G (2003): A prospective controlled trial on effect of percutaneous transluminal angioplasty on functioning arteriovenous hemo. J Am Soc Nephrol, Vol.14, No.6, (June, 2003), pp. 1623-1627, PMID 12761264

Turmel-Rodrigues L, Pengloan J \& Rodrigue H, Pengloan J, Rodigue H, Brillet G, Lataste A, Pierre D, Jourdan JL \& Blansard D (2000), Treatment of failed native arteriovenous fistulae for hemodialysis by interventional radiology. Kidney Int, 57(3), (March, 2000), pp. 1124-1140, PMID 10720965

Twardowski ZJ, Kubara H. (1979) Different sites vs. constant sites of needle insertion into arteriovenous fsitulas for treatment by repeated dialysis. Dial Transplant, Vol.8, pp. 978-980

Verhallen AM, Kooistra MP, Jaarsveld BC. (2007) Cannulating in heaemodialysis: ropeladder or buttonhole technique? Nephrol Dial Transplant, Vol.22, No.9, (September, 2007) pp. 2601-2604, PMID 1755776

Vazquez MA. (2009) Vascular access for dialysis: recent lessons and new insights. Current Opinions in Nephrology and Hypertension, 18 (2), (March, 2009), pp. 116-121, PMID 19434049 
Waltz P, Ladowski JS, Hines A. (2007) Distal Revascularization and interval ligation (DRIL) procedure for the treatment of ischemic steal syndrome after arm arteriovenous fistula. Annals of Vasc Surgery Vol. 21, No.4, (July, 2007), pp. 468-473, PMID 17419003

Wedgewood KR, Wiggins PA, Guillou PJ. (1984) A prospective study of end-to-side verses side-to side arteriovenous fistulas for hemodialysis Br J Surg Vol.71, No.8, (August, 1984) pp. 640-642, PMID 6743990

Wali MA, Eid RA, Dewan M, Al-Homrany MA. (2006) Pre-existing histopathological Changes in the cephalic vein of renal failure patients before arterio-venous fistula (AVF) construction AnnThorac Cardiovasc Surg 2006, Vol.12, No.5, (October, 2006), pp.341-348, PMID 17095976

US Renal Data System, USRDS (2009) Annual Data Report: Atlas of chronic kidney disease and end-stage renal disease in the United States. National Institute of Health, National Institute of Diabetes and Digestive and Kidney Disease: Bethesda Maryland, http:/ /www.usrds.org 


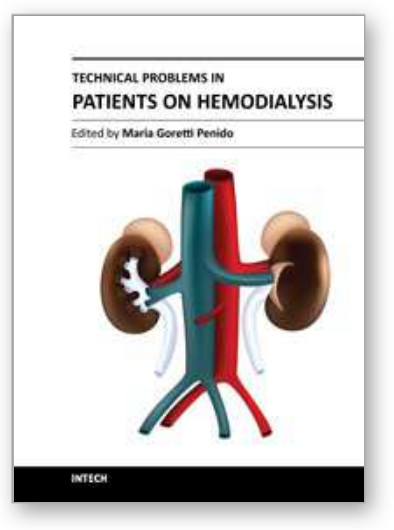

\author{
Technical Problems in Patients on Hemodialysis \\ Edited by Prof. Maria Goretti Penido
}

ISBN 978-953-307-403-0

Hard cover, 312 pages

Publisher InTech

Published online 07, December, 2011

Published in print edition December, 2011

This book provides an overview of technical aspects in treatment of hemodialysis patients. Authors have contributed their most interesting findings in dealing with hemodialysis from the aspect of the tools and techniques used.Each chapter has been thoroughly revised and updated so the readers are acquainted with the latest data and observations in the area, where several aspects are to be considered. The book is comprehensive and not limited to a partial discussion of hemodialysis. To accomplish this we are pleased to have been able to summarize state of the art knowledge in each chapter of the book.

\title{
How to reference
}

In order to correctly reference this scholarly work, feel free to copy and paste the following:

Mary Hammes (2011). Hemodialysis Access: The Fistula, Technical Problems in Patients on Hemodialysis, Prof. Maria Goretti Penido (Ed.), ISBN: 978-953-307-403-0, InTech, Available from:

http://www.intechopen.com/books/technical-problems-in-patients-on-hemodialysis/hemodialysis-access-thefistula

\section{INTECH}

open science | open minds

\section{InTech Europe}

University Campus STeP Ri

Slavka Krautzeka 83/A

51000 Rijeka, Croatia

Phone: +385 (51) 770447

Fax: +385 (51) 686166

www.intechopen.com

\section{InTech China}

Unit 405, Office Block, Hotel Equatorial Shanghai

No.65, Yan An Road (West), Shanghai, 200040, China

中国上海市延安西路65号上海国际贵都大饭店办公楼 405 单元

Phone: +86-21-62489820

Fax: +86-21-62489821 
(C) 2011 The Author(s). Licensee IntechOpen. This is an open access article distributed under the terms of the Creative Commons Attribution 3.0 License, which permits unrestricted use, distribution, and reproduction in any medium, provided the original work is properly cited. 